\title{
CONSERVAÇÃO E QUALIDADE DE MANGAS 'PALMER' SUBMETIDAS A TRATAMENTO COM FUNGICIDAS E HIDROTÉRMICO
}

\author{
Conservation and quality of 'Palmer' mangoes submitted \\ to treatment with fungicides and hydrothermal \\ Leandra Oliveira Santos ${ }^{1}$, José Fernando Durigan², \\ Ramilo Nogueira Martins ${ }^{3}$, Cristiane Maria Ascari Morgado
}

\begin{abstract}
RESUMO
Neste trabalho, objetivou-se testar o efeito de tratamento com fungicidas e sua combinação com hidrotérmico, na conservação e qualidade pós-colheita de mangas 'Palmer' (Mangifera indica L.) armazenadas sob condição ambiente por 12 dias. Os frutos foram colhidos no estádio de maturação fisiológica (coloração da casca vermelha arroxeada) e, imediatamente, transportados para o laboratório, onde foram padronizados quanto à coloração e ausência de injúrias e, em seguida, submetidos ao tratamento hidrotérmico $\left(53^{\circ} \mathrm{C} / 10\right.$ minutos), com os fungicidas, cloreto de dodecil dimetil amônio $12 \%$ a 120 ppm ou imazalil $50 \%$ a 1000 ppm, e associações destes tratamentos. Após secagem, as mangas foram armazenadas sob condição de ambiente $\left(23 \pm 2^{\circ} \mathrm{C}, 65 \pm 5 \% \mathrm{UR}\right)$ por 12 dias e analisadas quanto à ocorrência de podridões, aparência, coloração da casca e da polpa, perda de massa, firmeza, taxa respiratória, e teores de sólidos solúveis, acidez titulável e ácido ascórbico da polpa. O experimento foi conduzido em delineamento inteiramente casualizado, disposto em esquema fatorial com 5 x 5, com 4 repetições e unidade experimental composta de 9 frutos. Nos frutos, de todos os tratamentos, não se observou sinais de murchamento até o sexto dia de armazenamento. A associação do tratamento hidrotérmico com fungicidas não se mostrou eficiente no controle de podridões e não afetou o amadurecimento de mangas 'Palmer', que apresentaram vida útil de 10 dias a $23^{\circ} \mathrm{C}$, limitada pela aparência.
\end{abstract}

Termos para indexação: Antracnose, podridões, pós-colheita.

\begin{abstract}
The objective of this work was to test of effect of treatment with fungicides and its combination with hydrothermal on the conservation and pos-harvest quality of 'Palmer' mangoes (Mangifera indica L.) stored at atmosphere conditions for 12 days. The fruits had been harvested in the stages of physiological maturation (purple-red rind), transferred to the laboratory where they were separated by color and absence of injuries and then underwent hydrothermal (53 ${ }^{\circ} \mathrm{C}$ for $\left.10^{\prime}\right)$ and/or chemical treatment with the fungicides dodecil dimethyl ammonium chloride at $120 \mathrm{ppm}(12 \%)$ and imazalil at $1000 \mathrm{ppm}(50 \%)$. After drying, fruits were stored at room temperature $\left(23 \pm 2^{\circ} \mathrm{C}, 63 \pm 5 \% \mathrm{RH}\right)$ for 12 days and analyzed every three days for rots, appearance, coloration of the rind and the pulp, weight and firmness loss, respiratory rate, and levels of soluble solids, titable acidity and ascorbic acid in the pulp. The experiment was arranged in completely randomized design, in a 5 x 5 factorial scheme, with 4 replicates. Experimental units comprised nine fruits. No withering signs were observed in any of the treatments until the sixth day of storage. The combination of hydrothermal and fungicide treatments were not efficient in controlling rots. A shelf life of ten days was observed in 'Palmer' mangoes stored at $23^{\circ} \mathrm{C}$, which was limited by fruit appearance.
\end{abstract}

Index terms: Anthracnose, post harvest, rots.

(Recebido em 8 de outubro de 2008 e aprovado em 15 de julho de 2009)

\section{INTRODUÇÃO}

O Brasil é um dos maiores produtores de manga (Mangifera indica L.), com cerca de 950 mil toneladas no ano de 2004, sendo que as regiões nordeste e sudeste são responsáveis por $63 \%$ e $37 \%$ desta produção, respectivamente (Agrianual, 2007). Em razão de suas peculiaridades quanto ao aroma e sabor, além das excelentes condições nutritivas e possibilidades de seu cultivo no
Brasil, a manga passou a ser vista como uma alternativa frutícola, com boas perspectivas. Porém, com o aumento da demanda, bem como da produção, a incidência de pragas e doenças nessa cultura também aumentou. Uma das doenças mais importantes é a causada pelo fungo Colletotrichum gloeosporioides Penz, conhecida como antracnose. Outras podridões também são problemas à conservação pós-colheita da manga, como as podridões

\footnotetext{
"Universidade Estadual Paulista "Júlio de Mesquita Filho"/UNESP - Faculdade de Ciências Agrárias e Veterinárias/FCAV - Campus de Jaboticabal - Via de Acesso Professor Paulo Donato Castellane - s/n - 14884-9000 - Jaboticabal, SP - leandraoli@yahoo.com.br ${ }^{2}$ Universidade Estadual Paulista “Júlio de Mesquita Filho"/UNESP - Faculdade de Ciências Agrárias e Veterinárias/FCAV - Departamento de Tecnologia/DT Jaboticabal, SP

${ }^{3}$ Universidade Estadual Paulista "Júlio de Mesquita Filho"/UNESP - Faculdade de Ciências Agrárias e Veterinárias/FCAV - Jaboticabal, SP
} 
moles que têm sido atribuídas aos fungos Lasiodiplodia theobromae, Diplodia natalensis e Hendersonia creberrima (Choudhury \& Costa, 2004). Tem-se recomendado para o controle dessas podridões, após a colheita, a imersão dos frutos em água quente ou tratamento hidrotérmico em que a temperatura da água deve ser mantida constante, $55^{\circ} \mathrm{C}$, e os frutos imersos durante 5 minutos (Bleinroth, 1994). Esse autor também recomenda para uma maior eficiência a associação desse tratamento com fungicidas. Dias et al. (2005) associaram o tratamento hidrotérmico $\left(55^{\circ} \mathrm{C}\right)$, com o fungicida prochloraz e controlaram totalmente o aparecimento de sintomas de antracnose em mangas da cultivar Van Dike. No entanto, Filgueiras et al. (2000) recomendam que quando a imersão em água quente é combinada com fungicida sua temperatura deve ser reduzida para $52-53^{\circ} \mathrm{C}$.

Neste trabalho, objetivou-se testar o uso de tratamentos com fungicidas, combinados ou não com tratamento hidrotérmico, na conservação e qualidade póscolheita de mangas 'Palmer' armazenadas sob condição ambiente, por 12 dias.

\section{MATERIAL E MÉTODOS}

As mangas 'Palmer' foram colhidas manualmente em pomar comercial situado no município de TaquaritingaSP, no período da manhã, no estádio de maturação fisiológica com coloração da casca vermelha arroxeada e polpa correspondente ao grau 2 - 3 (mudança da cor da polpa de creme para amarela) da escala de coloração indicada pela Deutsche Gesellschaft für Technische Zusammenarbeit - GTZ (1992). Logo após a colheita, os frutos foram colocados em caixas plásticas e cuidadosamente transportados para o Laboratório de Tecnologia dos Produtos Agrícolas da Faculdade de Ciências Agrárias e Veterinárias, UNESP - Jaboticabal (SP). No laboratório, os frutos foram lavados em água corrente e seus pedúnculos padronizados em 10-20 mm, antes da seleção que visou a eliminar os com lesões mecânicas e uniformizar o estádio de maturação e o tamanho (peso médio de $460 \mathrm{~g}$ ). Depois de divididos em lotes, eles foram submetidos aos seguintes tratamentos: 1) Testemunha (sem tratamento); 2) imersão em calda fungicida de Sporekill ${ }^{\circledast}$ (cloreto de dodecil dimetil amônio $12 \%$ ) a 120 ppm (SPK); 3) imersão em calda fungicida Magnate $500 \mathrm{EC}^{\circledR}$, (imazalil 50\%) a 1000 ppm (IMA); 4) tratamento hidrotérmico $\left(53^{\circ} \mathrm{C} / 10 \mathrm{~min}\right.$.), seguido de imersão em fungicida Sporekill $\left.{ }^{\circledR}(\mathrm{HT}+\mathrm{SPK}) ; 5\right)$ tratamento hidrotérmico, seguido de imersão em fungicida Magnate $500 \mathrm{EC}^{\circledR}$ (HT + IMA). Os frutos foram armazenados sob condição ambiente $\left(23 \pm 2^{\circ} \mathrm{C}\right.$ e $\left.65 \pm 3 \% \mathrm{UR}\right)$, por 12 dias e, durante o período de armazenamento, foram amostrados 9 frutos por parcela, ao acaso, a cada três dias. Foram realizadas as seguintes análises: ocorrência de podridões, aparência, perda de massa, taxa respiratória, coloração da casca e da polpa, firmeza, sólidos solúveis, acidez titulável, pH e ácido ascórbico da polpa. Em cada tratamento, foram separadas três amostras com dois frutos cada para avaliação, a cada dois dias, da perda de massa fresca, evolução da aparência e aparecimento de podridões. A taxa de respiração dos frutos era determinada diariamente, em triplicata, utilizando-se dois frutos por repetição.

A aparência foi avaliada mediante a atribuição de notas, adotando-se os seguintes valores: 1 = frutos frescos, túrgidos, sem manchas e sem podridões; 2 = frutos com indícios de murchamento; e 3 = frutos murchos. Considerouse a nota 2 como o valor limite para sua vida útil ou comercial (Jerônimo \& Kanesiro, 2000).

O aparecimento de podridões foi detectado por observação visual, e indicado mediante a atribuição de notas, onde: $1=$ ausência de infecção; $2=$ lesões em até $10 \%$ dos frutos; $3=$ lesões em $10 \%$ a $30 \%$ dos frutos; $4=$ lesões em $30 \%$ a $50 \%$ dos frutos; e $5=$ lesões em mais de $50 \%$ dos frutos. A identificação dos patógenos foi feita por observação visual das estruturas do agente em microscópio óptico comum e comparação destas com o apresentado por Barnett \& Hunter (1972).

Para a determinação da porcentagem de perda de massa, foi considerada a diferença entre o peso inicial do fruto e aquele obtido a cada intervalo de tempo de amostragem, utilizando-se balança semianalítica, Marte modelo AS 2000, com precisão de $0,01 \mathrm{~g}$.

A respiração dos frutos foi avaliada colocando-se a amostra com 2 frutos, em recipiente hermeticamente fechado e com capacidade de $3 \mathrm{~L}$, por uma hora. Tomou-se alíquotas de $0,3 \mathrm{~mL}$ do ar, homogeneizado antes e depois desse tempo, nas quais se doseou o conteúdo de $\mathrm{CO}_{2}$. Estas amostras eram retiradas com microseringa Hamilton, dotada de válvula de contenção de gases, e analisadas em cromatógrafo gasoso CG Finnigan 9001. Esse aparelho é integrado por coluna Porapack-N (3,3 mm; 3,15 m), peneira molecular 5A (3,3 mm; 1,25 m), metanador e detectores de condutividade térmica $\left(150^{\circ} \mathrm{C}\right)$ e de ionização de chama $\left(150^{\circ} \mathrm{C}\right)$, e tem como gás de arraste o nitrogênio $\left(30 \mathrm{~mL} \mathrm{~min}^{-1}\right)$. $\mathrm{O}$ sistema opera com as colunas a $55^{\circ} \mathrm{C}$ e está acoplado a um sistema de computação com o "software" Borwin 2.2, o qual permite a integração dos picos obtidos e o cálculo das concentrações do $\mathrm{CO}_{2}$ em relação a uma mistura padrão contendo $10,00 \% \mathrm{O}_{2}$ e $0,10 \% \mathrm{CO}_{2}$ diluídos em $\mathrm{N}_{2}$, e 
fornecida pela White Martins. A quantidade de $\mathrm{CO}_{2}$ produzida no período, permitiu quantificar a intensidade respiratória dos materiais avaliados que foi expressa em $\mathrm{mg} \mathrm{CO} \mathrm{kg}^{-1} \mathrm{~h}^{-1}$ (Teixeira et al., 2005).

A coloração foi determinada utilizando-se um reflectômetro Minolta Croma Meter CR-200b, que se expressa segundo o sistema proposto pela Commission Internacionale de L'Eclaraige (CIE) e permite relatar a coloração pela luminosidade, ângulo Hue ou de cor e cromaticidade (Minolta Corp, 1994).

A firmeza da polpa foi determinada, usando-se um penetrômetro McCormick modelo FT 327, com ponteira cilíndrica de $8 \mathrm{~mm}$ de diâmetro e penetração de $7 \mathrm{~mm}$ na polpa. As avaliações foram feitas em duas regiões equidistantes, de lados opostos, da região equatorial dos frutos, após a remoção da casca. As leituras foram expressas em Newton.

O teor de sólidos solúveis foi determinado na polpa triturada em processador doméstico e a extração do suco em gaze, com posterior leitura direta e quantificação em refratômetro digital Atago PR-101 Palette e os resultados expressos em \% (Association of Official Analytical Chemists - AOAC, 1997).

A acidez titulável foi determinada por titulação com solução de $\mathrm{NaOH} 0,1 \mathrm{M}$, tendo-se como indicador a fenolftaleína $1 \%$ e os resultados expressos em gramas de ácido cítrico por $100 \mathrm{~g}$ de polpa (Instituto Adolfo Lutz, 1985).

Os teores de ácido ascórbico foram doseados em 10 gramas de polpa triturada e homogeneizada com $70 \mathrm{~mL}$ de ácido oxálico $0,5 \%$, a $5^{\circ} \mathrm{C}$, cujo filtrado teve seu volume completado para $100 \mathrm{~mL}$ com ácido oxálico $0,5 \%$. A quantificação foi feita por método titulométrico, usando-se 2,6 diclorofenolindofenol de sódio 0,1\% (Ranganna, 1977).

A perda de massa fresca foi analisada utilizando-se regressão polinomial e as equações comparadas quanto ao paralelismo, pelo do teste $\mathrm{t}$ (Neter et al., 1978).

$\mathrm{O}$ delineamento experimental foi o inteiramente casualizado (DIC), disposto em esquema fatorial $5 \times 5$, com 4 repetições e nove frutos por parcela, em que o primeiro fator correspondeu aos tratamentos, testemunha, com fungicidas, e suas associações com o tratamento hidrotérmico e o segundo, ao tempo de armazenamento, ou seja, $0,3,6,9$ e 12 dias. Cada parcela experimental foi composta de dois frutos. As médias foram comparadas pelo teste de Tukey, a nível de 5\% de significância. Para a descrição das variáveis, em função dos períodos de armazenamento, foram feitas análises de regressão e os modelos polinomiais foram selecionados observando-se a significância do teste $\mathrm{F}$ para cada modelo e coeficientes de determinação maiores que 0,70 (Gomes, 1977).

\section{RESULTADOS E DISCUSSÃO}

As mangas 'Palmer' não apresentaram podridões até $\mathrm{o}$ sexto dia de armazenamento sob condição ambiente, independentemente do tratamento utilizado (Figura 1A). A partir do oitavo dia, observou-se a presença de lesões de antracnose em todos os frutos, cujo agente causal é o Colletotrichum gloeosporioides Penz (Barnett \& Hunter, 1972).

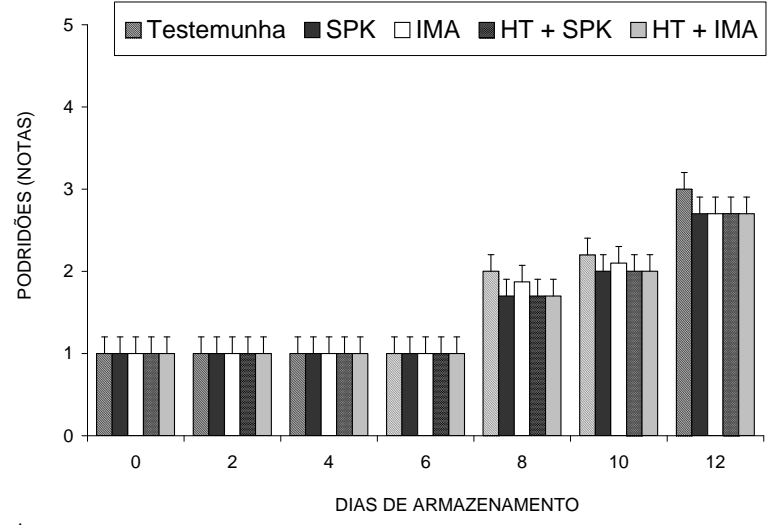

A

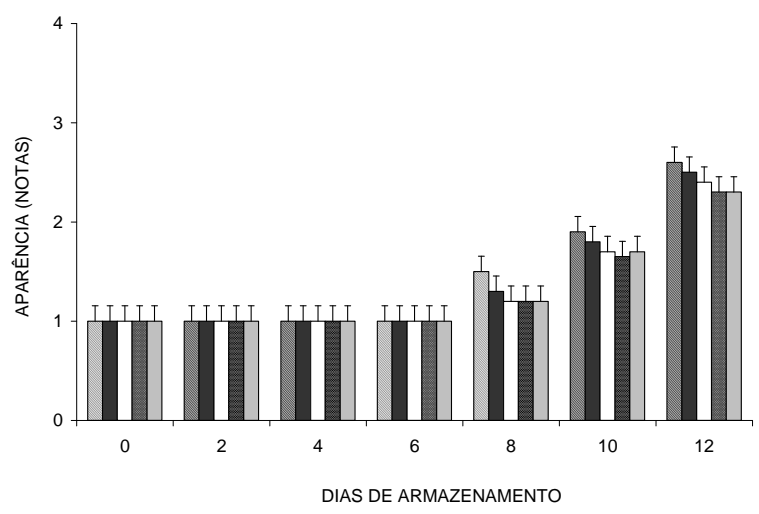

B

Figura 1 - Ocorrência de podridões (A) e evolução da aparência (B) em mangas 'Palmer' tratadas com fungicidas, associados ou não com tratamento hidrotérmico $\left(53^{\circ} \mathrm{C} / 10\right.$ minutos $)$ e armazenadas sob condição ambiente $\left(23^{\circ} \mathrm{C}, 65 \%\right.$ UR), por 12 dias. (Testemunha= sem tratamento; SPK= imersão em Sporekill ${ }^{\circledR}$ a 120 ppm; IMA= imersão em Magnate $500 \mathrm{EC}^{\circledR}$ a 1000 ppm; HT + SPK= tratamento hidrotérmico $\left(53^{\circ} \mathrm{C} / 10 \mathrm{~min}.\right)+$ imersão em Sporekill ${ }^{\circledR} ; \mathrm{HT}+\mathrm{IMA}=$ tratamento hidrotérmico + imersão em Magnate $500 \mathrm{EC}^{\circledR}$ ). 
Os frutos, independentemente dos tratamentos testados, apresentavam aceitação comercial (nota 2) até o $10^{\circ}$ dia (Figura $1 \mathrm{~B}$ ) e se mantiveram com aparência muito boa (nota 1 ), até o sexto dia.

Os resultados referentes à ocorrência de doenças (Figura 1A) e evolução da aparência (Figura 1B) indicam que os frutos de todos os tratamentos, armazenados sob condições ambiente, apresentaram aceitação comercial por até dez dias, com podridões em até $10 \%$ (Nota 2) e apenas alguns sinais de murchamento (Nota 2).

A perda de massa fresca das mangas aumentou de maneira constante, sem que houvesse diferença estatística entre os frutos sob diferentes tratamentos. Os frutos de todos os tratamentos, no $6^{\circ}, 8^{\circ}, 10^{\circ}$ e no final do período de armazenamento (12 dias), apresentavam, em média, perda de massa de $7,75 \%, 11,10 \%, 12,22 \%$ e $13,27 \%$, respectivamente. Jerônimo \& Kanesiro (2000), trabalhando com mangas 'Palmer' encontraram perda de massa da ordem de $11,56 \%$, após oito dias de armazenamento sob condição ambiente, o que reafirma o observado neste trabalho. Segundo Chitarra \& Chitarra (2005), perdas da ordem de $3 \%$ a $6 \%$ são suficientes para causar um marcante declínio na qualidade da maioria dos produtos hortícolas, porém, isto foi o observado para as mangas 'Palmer', que aos 10 dias de armazenamento apresentaram, em média, $12,22 \%$ de perda de massa com apenas alguns sinais de murchamento (Nota 2).
De acordo com a Figura 2, os frutos independentemente do tratamento aumentaram a taxa respiratória de $32 \mathrm{mg} \mathrm{CO}_{2} \mathrm{~kg}^{-1} \mathrm{~h}^{-1}$, no início, para até $96 \mathrm{mg} \mathrm{CO} \mathrm{kg}^{-1} \mathrm{~h}^{-1}$. Pode-se observar um aumento expressivo na produção de $\mathrm{CO}_{2}$ pelos frutos, a partir do sexto dia de armazenamento sob condição ambiente, sugerindo o climatério. Nos frutos tratados hidrotermicamente (HT + SPK e HT + IMA) a intensidade respiratória foi a menor, durante os primeiros sete dias de armazenamento.

O tempo de armazenamento afetou a coloração da casca das mangas 'Palmer', com base nas variáveis cromaticidade e ângulo Hue (Figura 3), enquanto para o valor L* a variação de 42,9 a 45,73 não foi significativa, o que é discordante do relatado por Jerônimo \& Kanesiro (2000) que observaram valores crescentes ao longo do período de armazenamento. Os valores de Hue indicam evolução da coloração da casca indicam evolução de verde claro $(130,44)$ para amarelo intenso $(120,47)$, com aumento na cromaticidade o que também foi relatado por Jerônimo \& Kanesiro (2000). Segundo Chitarra \& Chitarra (2005), as modificações na coloração dos frutos são decorrentes dos processos metabólicos, os quais correspondem a um dos principais critérios para a identificação do amadurecimento em frutas e hortaliças.

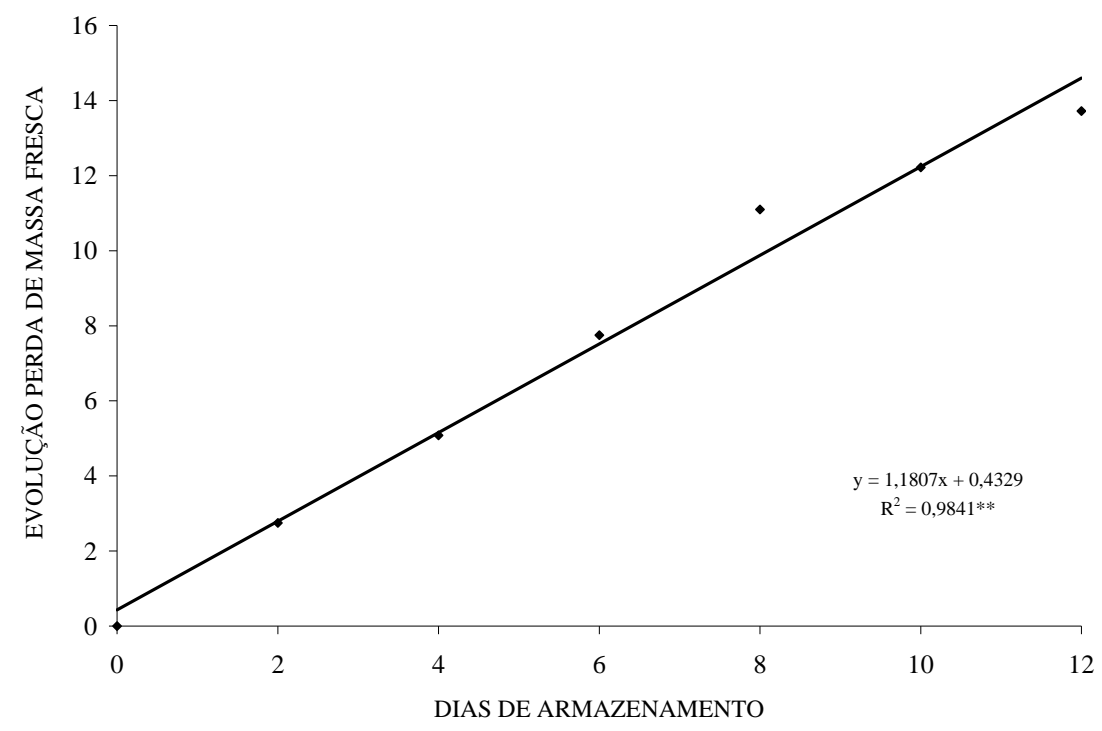

Figura 2 - Evolução da perda de massa fresca de mangas 'Palmer' tratadas com fungicidas, associados ou não com tratamento hidrotérmico $\left(53^{\circ} \mathrm{C} / 10\right.$ minutos) e armazenadas sob condição ambiente $\left(23^{\circ} \mathrm{C}, 65 \% \mathrm{UR}\right)$, durante 12 dias. 
Os tratamentos e o período de armazenamento não influenciaram o ângulo Hue $(106,98)$ e o valor L* $(84,95)$ da coloração da polpa das mangas 'Palmer', enquanto a cromaticidade aumentou durante o armazenamento, indicando aumento na intensidade de sua coloração amarelada (Figura 4A e 4B).

A firmeza da polpa não foi afetada pelos tratamentos, mas alterou-se significativamente durante o armazenamento, cuja resistência inicial, de 134,22 N, reduziu a 9,67 N, aos 12 dias, quando os frutos se apresentavam sobremaduros (Figura 5A). A redução na resistência foi mais intensa a partir do sexto dia de armazenamento, o que é coincidente com o climatério (Figura 3). Os valores de firmeza obtidos foram menores que os relatados por Hojo et al. (2007), 142,55 N, para mangas 'Palmer' verdes.

Os tratamentos também não afetaram o teor de sólidos solúveis da polpa das mangas 'Palmer', que foi significamente influenciado pelo tempo de armazenamento (Figura 5B). Observou-se aumento nos teores de sólidos solúveis de $6,39 \%$, no início, para $14,89 \%$ no décimo dia, quando os frutos estavam maduros e $16,02 \%$, no $12^{\circ}$ dia, o que também foi relatado por Bleinroth et al. (1985) ao caracterizar mangas desta cultivar, com teores de $13,50 \%$ a $17,49 \%$ quando madura.

A acidez titulável, no entanto, apresentou tendência de diminuição durante o período de armazenamento, em todos os tratamentos, sendo que, após o sexto dia, observou-se decréscimo mais acentuado (Figura 5C). Esse comportamento pode ser decorrente da redução do metabolismo que leva a declínio na concentração de ácidos orgânicos dos frutos (Kays, 1991; Jerônimo \& Kanesiro, 2000).

Os teores de ácido ascórbico foram influenciados apenas pelo tempo de armazenamento (Figura 5D), com variação de $37,27 \mathrm{mg} 100 \mathrm{~g}^{-1}$ para $30,56 \mathrm{mg} 100 \mathrm{~g}^{-1} \mathrm{de}$ polpa, os quais são superiores aos encontrados por Jerônimo \& Kanesiro (2000), quando armazenaram frutos da cultivar 'Palmer' e por Bleinroth et al. (1985) que analisaram a polpa de frutos maduros, de diversas cultivares de manga, e encontraram teores variando de

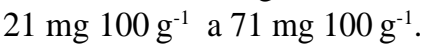

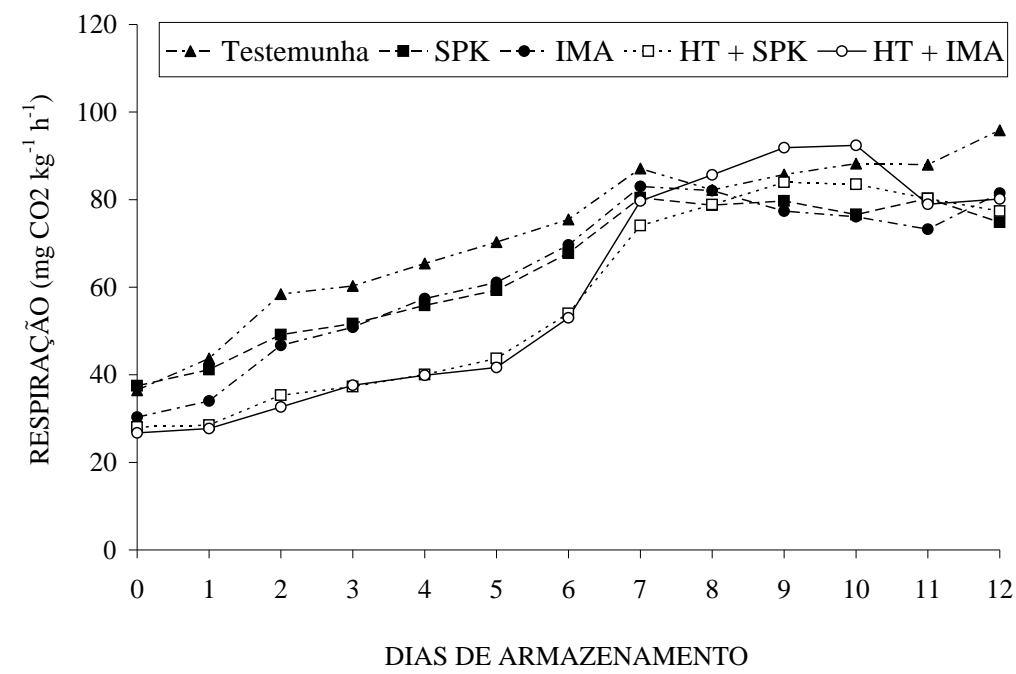

Figura 3 - Taxa respiratória de mangas 'Palmer' tratadas com fungicidas, associados ou não com tratamento hidrotérmico $\left(53^{\circ} \mathrm{C} / 10\right.$ minutos) e armazenadas sob condição ambiente $\left(23^{\circ} \mathrm{C}, 65 \% \mathrm{UR}\right)$, por 12 dias. (Testemunha= sem tratamento; $\mathrm{SPK}=$ imersão em Sporekill ${ }^{\circledR}$ a 120 ppm; IMA= imersão em Magnate $500 \mathrm{EC}^{\circledR}$ a 1000 ppm; HT + SPK= tratamento hidrotérmico $\left(53^{\circ} \mathrm{C} / 10\right.$ min. $)+$ imersão em Sporekill ${ }^{\circledR} ; \mathrm{HT}+\mathrm{IMA}=$ tratamento hidrotérmico + imersão em Magnate $\left.500 \mathrm{EC}^{\circledR}\right)$. 

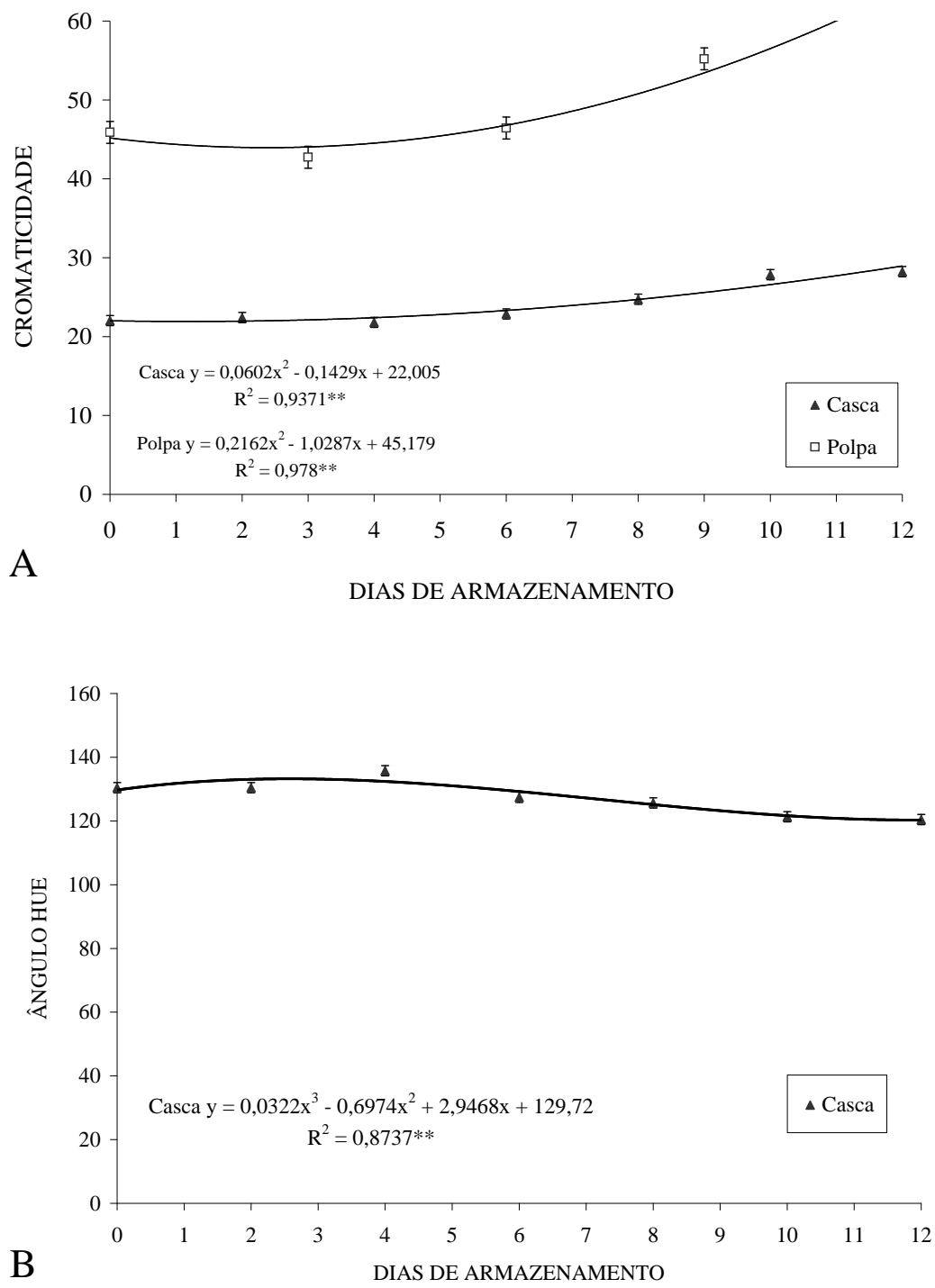

Figura 4 - Cromaticidade (A) e ângulo Hue (B) da casca e da polpa de mangas 'Palmer' tratadas com fungicidas, associados ou não com tratamento hidrotérmico $\left(53^{\circ} \mathrm{C} / 10\right.$ minutos) e armazenadas sob condição ambiente $\left(23^{\circ} \mathrm{C}, 65 \%\right.$ $\mathrm{UR})$, por 12 dias. 

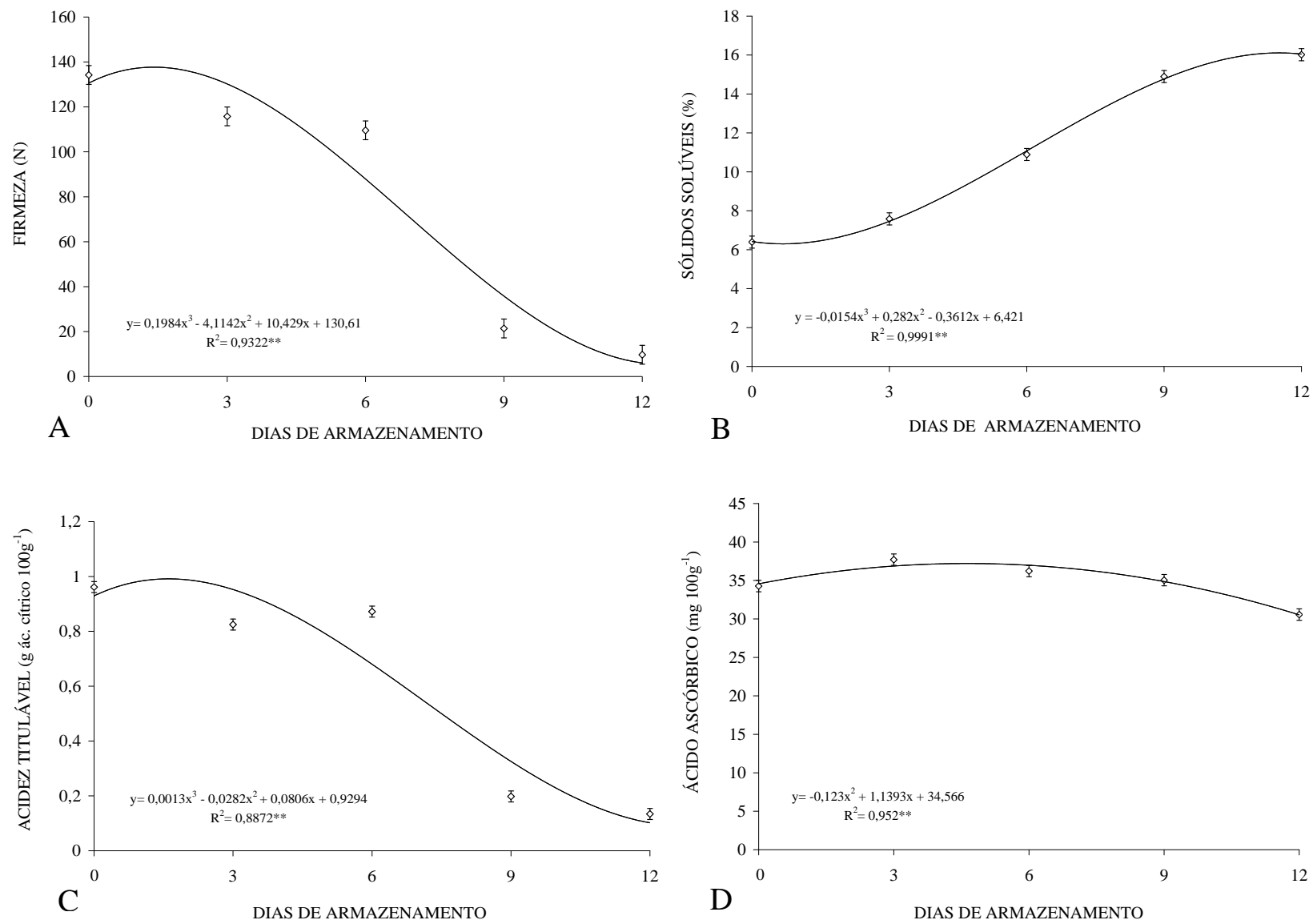

Figura 5 - Firmeza (A), e teores de sólidos solúveis (B), acidez titulável (C) e ácido ascórbico (D) da polpa de mangas 'Palmer' tratadas com fungicidas, associados ou não com tratamento hidrotérmico $\left(53^{\circ} \mathrm{C} / 10\right.$ minutos $)$, e armazenadas sob condição ambiente $\left(23^{\circ} \mathrm{C}, 65 \% \mathrm{UR}\right)$, por 12 dias.

\section{CONCLUSÕES}

O uso de fungicidas testados, associados ou não ao tratamento hidrotérmico, não se mostrou eficiente no controle de podridões, assim como não afetou o amadurecimento de mangas 'Palmer', expresso pela evolução da firmeza, coloração da polpa e da casca e teores de sólidos solúveis, acidez titulável e ácido ascórbico da polpa, cuja vida útil foi de 10 dias, sob condição ambiente, limitada pela aparência.

\section{AGRADECIMENTOS}

A Fundação de Amparo à Pesquisa do Estado de São Paulo (Proc.05/58381-3) pela bolsa de estudos e ao produtor, Sr. Ademar Ogata, pelo fornecimento dos frutos.

\section{REFERÊNCIAS BIBLIOGRÁFICAS}

AGRIANUAL. Anuário da agricultura brasileira. São Paulo: FNP Consultoria e Comércio, 2007. 386p.

\section{ASSOCIATION OF OFFICIALANALYTICAL CHEMISTS. Official methods of analysis of the Association of Official Analytical Chemists} International. 3.ed. Washington, 1997. v.2, p.37-45.

BARNETT, H.L.; HUNTER, B.B. Illustrated genera of imperfect fungi. Minneapolis: Beugess, 1972. 241p.

BLEINROTH, E.W. Determinação do ponto de colheita. In: _. Manga para exportação: procedimentos de colheita e pós-colheita. Brasília: MAARA/FRUPEX, 1994. p.11-27. (Série Publicações Técnicas). 
BLEINROTH, E.W.; FILGUEIRAS, L.B.; VEIGA, A.A. Avaliação de novas cultivares de manga para industrialização: 1., análise das características físicogeométricas e químicas da matéria-prima. Boletim do Instituto de Tecnologia de Alimentos, Campinas, v.22, n.2, p.207-216, 1985.

CHITARRA, M.I.F.; CHITARRA, A.B. Pós-colheita de frutas e hortaliças: fisiologia e manuseio. 2.ed. Lavras: UFLA, 2005. 785p.

CHOUDHURY, M.M.; COSTA, T.S. Perdas na cadeia de comercialização da manga. Petrolina: Embrapa SemiÁrido, 2004.41p. (Documentos, 186).

\section{DEUTSCHE GESELLSCHAFT FÜR TECHNISCHE} ZUSAMMENARBEIT. Manual de exportación: frutas tropicales y hortalizas. Eschborn, 1992. 34p.

FILGUEIRAS, H.A.C.; MENEZES, J.B.; AMORIM, T.B.F.; ALVES, R.E.; CASTRO, E.B. de. Características da fruta para exportação. In: FILGUEIRAS, H.A.C. Manga: pós-colheita. Brasília: Embrapa Comunicação para Transferência de Tecnologia, 2000. p.14-21. (Frutas do Brasil, 2).

GOMES, F.P. Curso de estatística experimental. Piracicaba: Nobel, 1977. 430p.

HOJO, E.T.D.; ABREU, C.M.P. de; HOJO, R.H.; ASMAR, S.A.; CUNHA JÚNIOR, L.C.; CORRÊA, A.D. Firmeza de mangas Palmer tratadas com 1metilciclopropeno e armazenadas sob refrigeração. Ciência e Agrotecnologia, Lavras, v.31, n.6, p.18781883, 2007.
INSTITUTO ADOLFO LUTZ. Normas analíticas: métodos químicos e físicos para análises de alimento. 2.ed. São Paulo, 1985. v.1, 371p.

JERÔNIMO, E.M.; KANESIRO, M.A.B. Efeito da associação de armazenamento sob refrigeração e atmosfera modificada na qualidade de mangas 'Palmer'. Revista Brasileira de Fruticultura, Jaboticabal, v.22, n.2, p.237-243, 2000.

KAYS, S.J. Postharvest physiology of perishable plant products. Athens: AVI, 1997. 532p.

MEGALE, J. Influência do estádio de maturação e da condição de armazenagem em parâmetros sensoriais, químicos e microbiológicos de manga, cultivar Palmer, semi processada. 2002. 111f. Dissertação (Mestrado em Engenharia Agrícola)-Universidade Estadual de Campinas, Campinas, 2002.

MINOLTA CORP. Precise color communication: color control from feeling to instrumentation. Ramsey: Minolta Corporation Instrument Systems Division, 1994. 49p.

NETER, J.; WASSERMAN, W.; WHITMORE, G.A. Applied linear statistical models. Massachussetts: Allyn and Bacon, 1978. 745p.

RANGANNA, S. Manual of analysis of fruit and vegetable products. New Delhi: McGraw-Hill, 1977. 634p.

TEIXEIRA, G.H.A.; DURIGAN, J.F.; ALVES, R.E.; O'HARE, T.J. Use of carambola (Averrhoa carambola L. 'Fwang Tung') fruit at two stages of maturity for fresh-cut products. Acta Horticulturae, Leuven, v.682, p.1901-1908, 2005. 